\title{
Simulations Analysis with Comparative Study of a PMSG Performances for Small WT Application by FEM
}

\author{
H. Mellah", K. E. He ms as \\ Department of Electrical en gineering, Setif1 University, Algeria
}

\begin{abstract}
Permanent magnet synchronous generators (PMSGs) have a bright prospect in the small wind turbine (WT) applications; PMSGs compared to the conventional electrically excitated generators have many advantages, that's why they have attracted many and a strong interest of research. In this paper, a comparative PMSG performance study's is presented, these performances is studied as a function of physical material like the type of permanent magnet (high, poor, average and linear), as a function of the environmental conditions as rotor speed, finally, as a function of the design and geometrical parameters (rotor length, number of poles, number of stator slots). These results are obtained by finite element method (FEM); this approach is a powerful and useful tool to study and design PMSGs, as represented in this paper.
\end{abstract}

Keywords Cogging Torque, Finite Element Analysis, PMSG, Nu mber of Poles, Nu mber of Stator Slot, Wind Energy

\section{Introduction}

There is now general acceptance that the burning of fossil fuels is having a significant influence on the global climate. Effective mitigation of climate change will require deep reductions in greenhouse gas emissions, with UK estimates of a $60-80 \%$ cut being necessary by $2050[1]$, Still purer with the nuclear power, this last leaves behind dangerous wastes for thousands of years and risks contamination of land, air, and water[2]; the catastrophe of Japan is not far. Wind power can contribute to fulfilling several of the national environmental quality objectives decided by Parliament in 1991. Continued expansion of wind power is therefore of strategic importance[3], hence, the energy policy decision states that the objective is to facilitate a change to an ecologically sustainable energy production system[3], as example the Swedish Parliament adopted new energy guidelines in 1997 following the trend of moving towards an ecologically sustainable society. The decision also confirmed that the 1980 and 1991 guidelines still apply, i.e., that the nuclear power production is to be phased out at a slow rate so that the need for electrical can be met without risking employment and welfare. The first nuclear reactor of Barseback was shut down 30th of November 1999; Nuclear power production shall be replaced by improving the efficiency of electric ity use, conversion in the renewable forms of energy and other environmentally acceptable electricity production technologies [3].

* Corresponding author: Mellah hacene

has.mel@gmail.com (H. Mellah)

Published online at http://journal.sapub.org/ijee

Copyright (C) 2013 Scientific \& Academic Publishing. All Rights Reserved
On the individual scale in Denmark Poul la Cour, who was among the first to connect a wind mill to a generator[4]. The development of modern wind power conversion technology has been going on since 1970s, and the rapid development has been seen from 1990s. Various WT concepts have been developed and different wind generators have been built[5]. In real wind power market, three types of wind power system for large WTs exist. The first type is fixed-speed wind power (SCIG), directly connected to the grid. The second one is a variable speed wind system using a DFIG or SCIG. The third type is also a variable speed WT, PMSG[6].

\section{PMSG in Wind Turbine Application}

In literatures many types of generator concepts have been proposed and used. Most of the low speed WT generators presented are PMSGs[7]. Fig. 1 shows the scheme of PMSG for direct-drive WTs connected o grid.

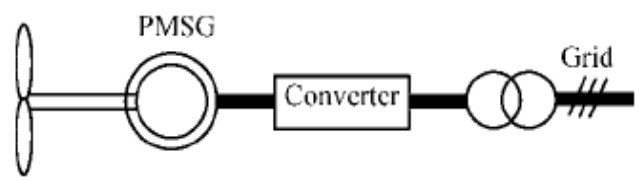

Figure 1. Scheme of a direct-drive PMSG system

Recent studies show a great demand for small to medium rating (up to $20 \mathrm{~kW}$ ) wind generators for stand-alone generation-battery systems in remote areas. The type of generator for this application is required to be compact and light so that the generators can be conveniently installed at the top of the towers and directly coupled to the WTs[7]. In addition there are several reasons for using variable-speed operation of WTs; the advantages are reduced mechanical 
stress and optimized power capture. Because of the variab le speed operation, the direct-drive PMSG system can produce $5-10 \%$ more energy than the fixed two-speed concept, or $10-15 \%$ more than the fixed single-speed concept[8].

Compared to a conventional, gearbox coupled WT generator, directly coupled generators has a series of advantages, such as a much reduced size of the overall system, a rather low installation and maintenance cost, flexible control method, quick response to the wind fluctuation and load variations, etc. However, a directly coupled generator needs to have a very low-speed operation to match the WT speed and, at the same time, to produce electric ity in a normal frequency range $(10-60 \mathrm{~Hz})[7]$.

Compared with electrically excited machines, PMSG have a number of economical and technical advantages, so that they are becoming more attractive for direct-d rive WTs, these advantages can be summarised as follows according to literatures [5-8]:

- higher efficiency and energy yield,

- no additional power supply for the magnet field excitation,

- improvement in the thermal characteristics of the PMM due to the absence of the field losses,

- higher reliability due to the absence of mechanical components such as slip rings,

- lighter and therefore higher power to weight ratio.

However, PMMs have some disadvantages, which can be summarised as follows:

- Relatively new and unknown technology for applications in larger MW-range

high cost of PM material,

difficulties to handle in manufacture,

- Low material reliability in harsh atmospheric conditions (offshore)

- demagnetisation of PM at high temperature.

On the other hand, in recent years, the use of PMs is more attractive than before, because the performance of PMs is improving and the cost of PM is decreasing[8].

Currently, Zephyros (currently Harakosan) and Mitsubishi are using this concept in 2 MW WTs in the market.

PMM are not standard off-the-shelf machines and they allow a great deal of flexibility in their geometry, so that various topologies may be used[8].

One can noticed two problems of PMSG used in wind power. First is the inherent cogging torque due to magnet materials naturally attractive force. This kind of torque is bad for operation, especially stopping WT starting and making noise and vibration in regular operation. The other one is the risk of demagnetization because of fault happening and overheating of magnets. This risk is very dangerous and the cost for replacing bad magnets is much higher than the generator itself[5].

\section{PM Material Used in PMSG Design}

The application requirement decides the type of PM material used due to cost, size and weight. It is very important to consider operating temperature range, weight constraint, external demagnetizing field and space limitation at design stage itself. Commercial type PMM uses ceramic or polymer-bonded neodymium-iron boron magnets [7].

The first known apparatus exploiting magnetism was a magnetic compass, invented by the Chinese around 3000 BC. An important milestone in the research field of magnetis $m$ was set in 1600 when William Gilbert published his book "De Magnete"[9]. Fig. 2 shows the historical development of the rare earth magnets.

In $1931 \mathrm{~T}$. Mishima patented the first hard magnetic alloy, based on aluminium, nickel and iron. This was the start of the development of the PM family known as AINiCo. In the 1950s, another PM family, known as ferrites, became commercially available. The development of rare earth PM materials started in the 1960's with the Samarium-Cobalt alloys. The material properties of $\mathrm{SmCo} 5$ and $\mathrm{Sm} 2 \mathrm{Co} 17$ make these PM materials very suitable to be used in electric motors and generators, but they are expensive due to the rare raw material Cobalt[9].

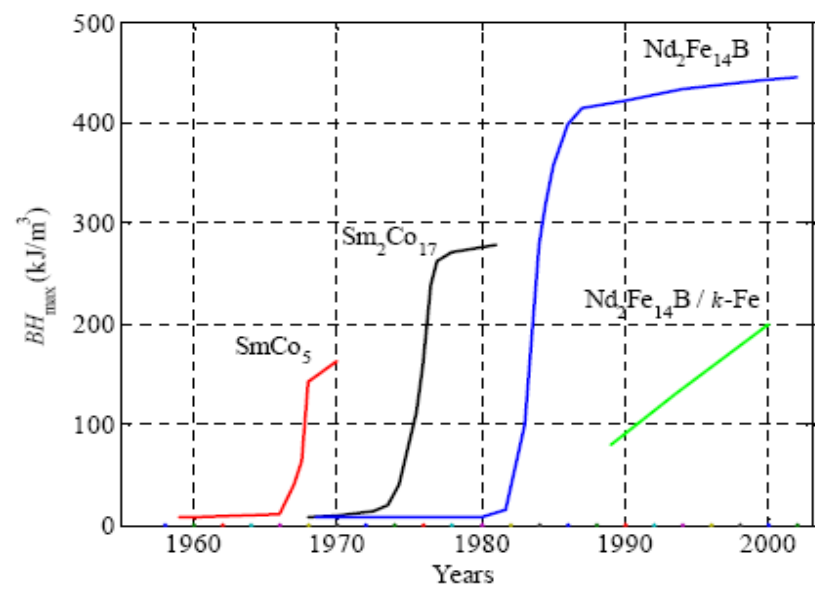

Figure 2. Historical development of the rare earth magnets[9]

In 1983 is the most important development in PM used in PMM it is the invention of the high-performance Neodymium-Iron-Boron (Nd-Fe-B), since that, the development of the PMSM has been fast, especially low-speed and variable speed industrial applications [9], this material has a very low Curie temperature and high temperature sensitivity. It is often necessary to increase the size of magnets to avoid demagnetization at high temperatures and high currents[10], Recently, Nd-Fe-B magnet material with remanence a flux density $\mathrm{Br}$ of $1.52 \mathrm{~T}$ and a maximum energy product of $440 \mathrm{~kJ} / \mathrm{m} 3$ was reported. An Nd-Fe-B magnet material of this grade has become commercially available since the year 2004. The best $\mathrm{Nd}-\mathrm{Fe}-\mathrm{B}$ grades, capable of tolerating temperatures up to $200^{\circ} \mathrm{C}$, have remanence flux densities of about $1.2 \mathrm{~T}$ and have their maximum energy product of $300 \mathrm{~kJ} / \mathrm{m} 3$ at a $20^{\circ} \mathrm{C}$ temperature[9]. 


\section{Methodology Design Used in PMSG Software}

Traditionally, the study and design of PMSGs is based on the equivalent magnetic circuit method (EMCM). The EMCM is of advantages of simplicity and fast computation, but its disadvantage is also marked: it relies too much on empirical design experience, such as flux leakage coefficient, armature reaction factor, etc. Meanwhile, under certain circumstances, EMCM is not competent for the analysis and design of PMSGs. For example, EMCM cannot be employed to study the cogging torque of PMSGs with fractional stator slots[11]. Numerical methods, such as finite-element analysis (FEA), have been extensively used in study and design PMSGs[11-12], Furthermore, owing to its precision and simplicity, the two-dimensional (2-D) FEM has approximately dominated the FEM study of PMSGs. By using FEM, many design curves and data, such as the PMSGs' output voltage, no-load leakage flux coefficient, and cogging torque etc., can be obtained and used to design PMSGs[11], In addition, many commercially available computer-aided design (CAD) packages for PM motor designs, such as SPEED, Rmxprt, and flux2D, require the designer to choose the sizes of magnets. The performance of the PM motor can be made satisfactory by constantly adjusting the sizes of magnets and/or repeated FEA analys es[12].

\section{Simulation Results}

The FEA model of electromagnetic field is built by Maxwe 112D, This simulation is obtained by Terra pc (QuadroFX380, i7 CPU, 3.07 GHZ, 8 CPU, 4 G RAM), and the simulation time is take some hours. Our model of PMSG used in Maxwell environ ment has 2138 triangles.

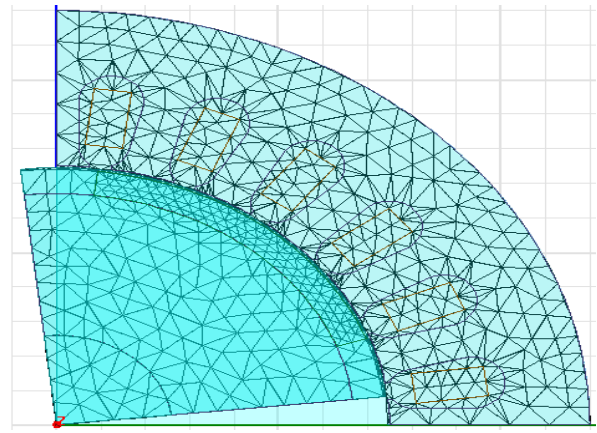

Figure 3. Geometry and FE mesh of the half PMSG

\subsection{Perfor mance of $P M S G$ at Different $P M$}

The permanent-magnetic steel symbolized (XG196/96), possesses residual flux density 0.96 Tesla, coercive force $690 \mathrm{kA} / \mathrm{m}$, maximum magnetic energy product $183 \mathrm{~kJ} / \mathrm{m} 3$, and relative recoil magnetic permeability 1.0.[13].

Fig. 4 shows the AirGap power of the same PMSG in different types PM, Ndfe 35 is $7.5 \mathrm{~kW}, \mathrm{XG}$ almost $6 \mathrm{KW}$, ciramic $8 \mathrm{~d} 1 \mathrm{KW}$, the bad is Alnico $50,5 \mathrm{KW}$.
Table 1. PMPropriety Used in this Simulation[13]

\begin{tabular}{|c|c|c|c|}
\hline & $\begin{array}{c}\text { Coercive } \\
\text { force } \\
\mathrm{Hc}[\mathrm{Am}]\end{array}$ & $\begin{array}{c}\text { Residual flux } \\
\text { density } \\
\mathrm{Br}[\mathrm{T}]\end{array}$ & $\begin{array}{c}\text { Maximum magnet ic } \\
\text { energy product } \\
\mathrm{BHmax}[\mathrm{kJ} / \mathrm{m} 3]\end{array}$ \\
\hline Alnico5 & -640 & 1.27 & 5508 \\
\hline $\mathrm{XG196/96}$ & -690000 & 0.96 & 183 \\
\hline Ceramic8D & -266585 & 0.4 & 30.637 \\
\hline NdFe35 & -890000 & 1.23 & \\
\hline
\end{tabular}

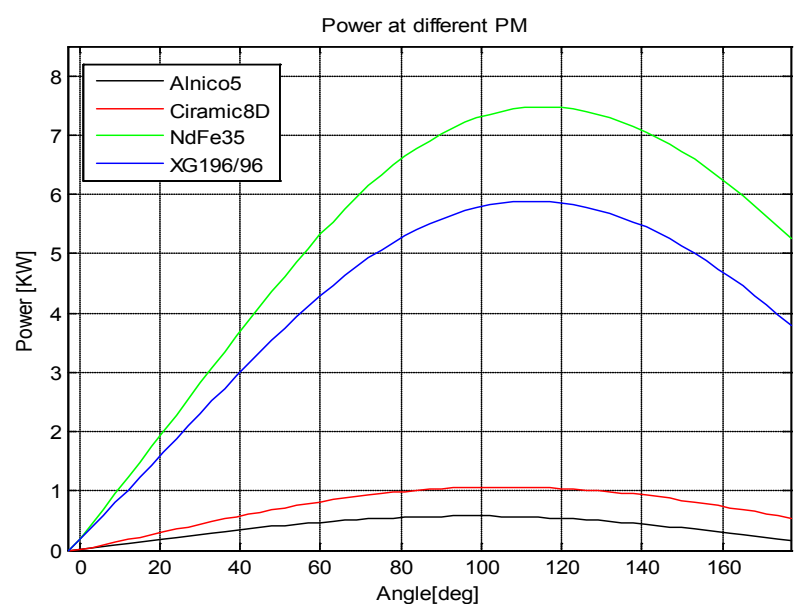

Figure 4. Power vs angle degree at different PM

Fig. 5 compare the flux density distribution variation vs electrical degree at different PM, when it is noted that Ndfe 35 gives the most important value of flux density, this value is more than $0,8 \mathrm{~T}$.

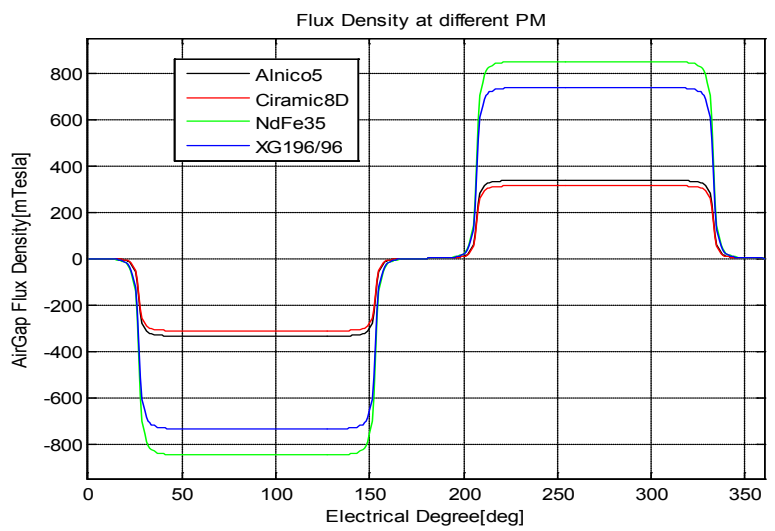

Figure 5. Flux density distribution vs electrical degree at different PM

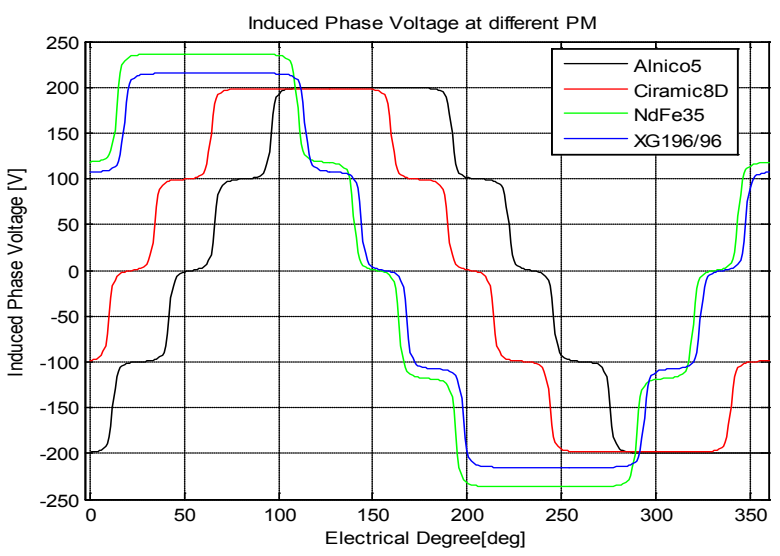

Figure 6. Induced phase voltage vs electrical degree at different PM 
Fig. 6 illustrate the induced phase voltage vs electrical degree of PMSG curves at different PM, it is seen that NDF35 induce the most intense voltage of value $236,2 \mathrm{~V}, \mathrm{XG}$ provide $215,22 \mathrm{~V}$, A lnico5 and Ciramic $8 \mathrm{D}$ give the same Induced Phase Voltage 200V.



Figure 7. Cooging torque vs electrical degree at different PM

Fig. 7 shows a comparis on between the cogging torque vs electrical degree at different PM, In this case, the NDF35 gives higher amplitude values for the cogging torque, the order of amplitude values of cogging torque are $\mathrm{XG}$, Alnico5 and Ciramic 8D respectively, but the curvatures are similar.

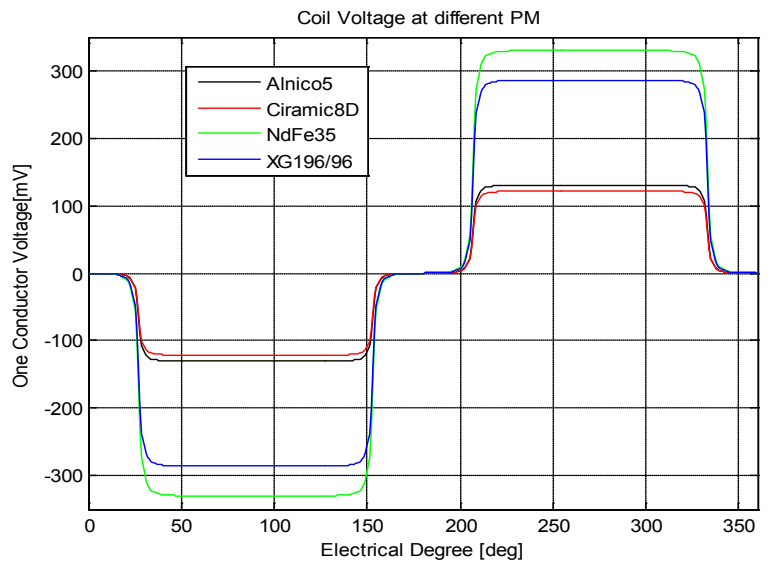

Figure 8. One coil voltage vs electrical degree at different PM type

Fig. 8 shows the waveforms of the one coil voltage vs electrical degree as a function of PM type, the NDF35 gives higher amplitude values for the coil voltage, the order of amplitude values of cogging torque is $\mathrm{XG}$, Alnico5 and Ciramic $8 \mathrm{D}$ respectively, but the curvatures are similar.

\subsection{Influence of $S$ peed Variation in $P$ MS G Perfor mance}

In this simulation case, the objective is to see the effect of speed variation on the PMSG characteristics.

Fig. 9 shows the waveform of the one coil voltage vs electrical degree as a function of rotor speed, we can say that the relation between the rotor speed and one coil voltage is proportional, but the curvatures are similar. Fig. 10 Illustrate the efficiency vs rotor position angle at different rotor speed, so that more than the rotor turns at a high speed the efficiency increases in amplitude and broad in axis of the angles.



Figure 9. One coil voltage vs electrical degree at different speed 


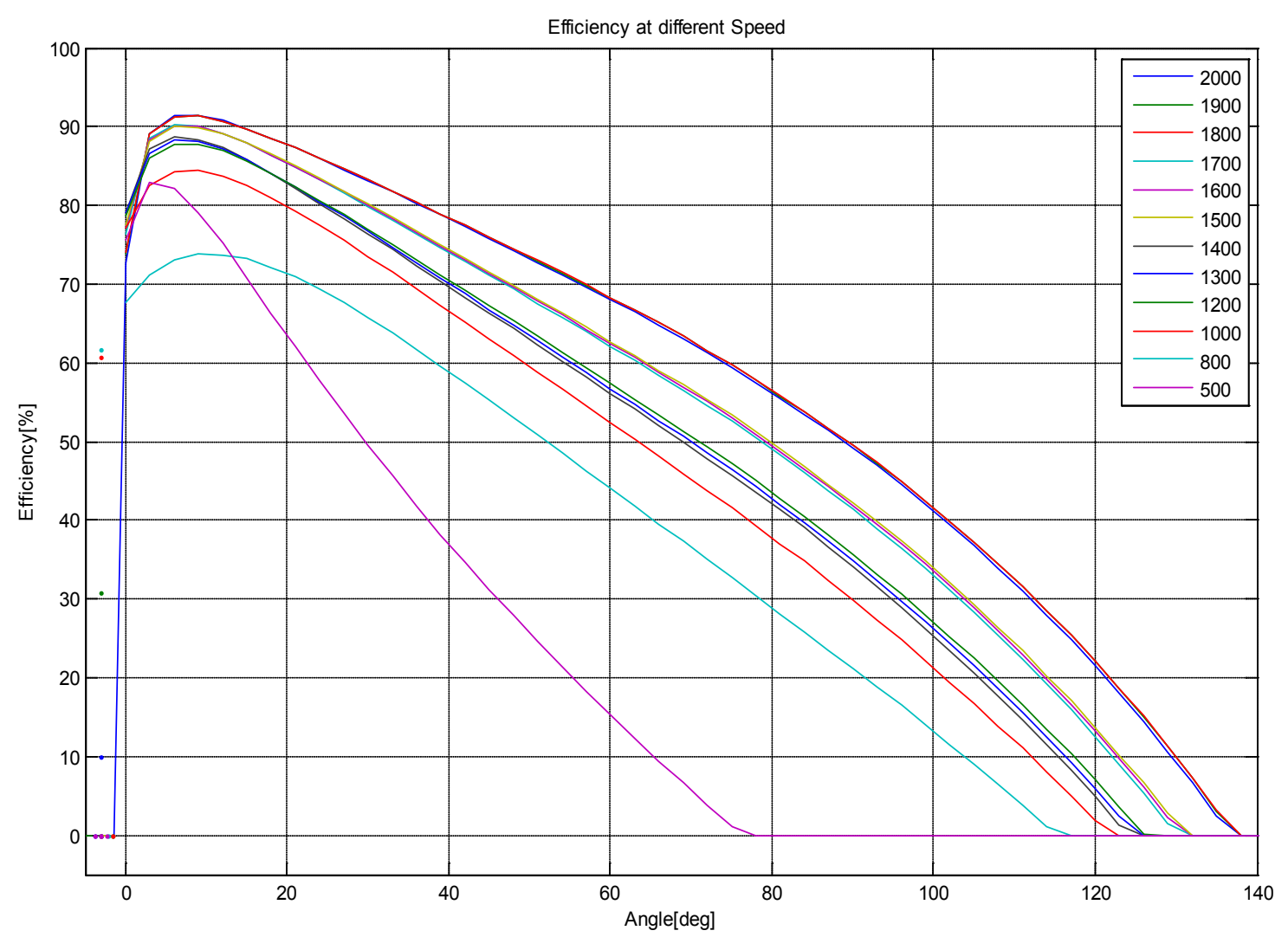

Figure 10. Efficiency vs angle degree at different speed

We can notice the influence of the rotational speed on the power in the figure 11 , one can see clearly that the relation between speed and the power is proportional, but the curvatures are similar, the maximum of power provided by PMSG is $7.8 \mathrm{KW}$ corresponds at the speed 2000rpm, and the minimu m equal to $2.69 \mathrm{KW}$ corresponds at the speed $800 \mathrm{rpm}$.

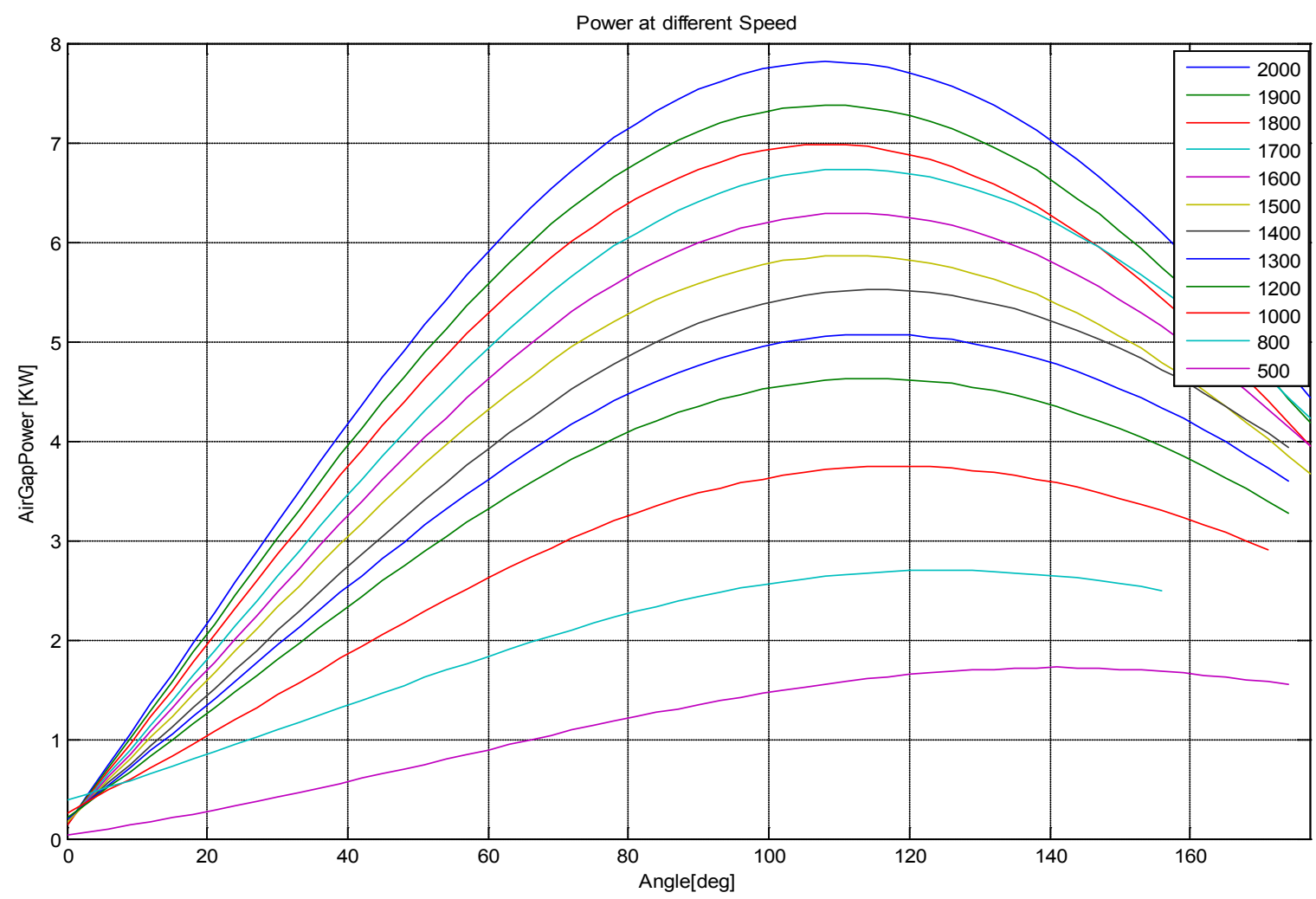

Figure 11. Power vs angle degree at different speed 


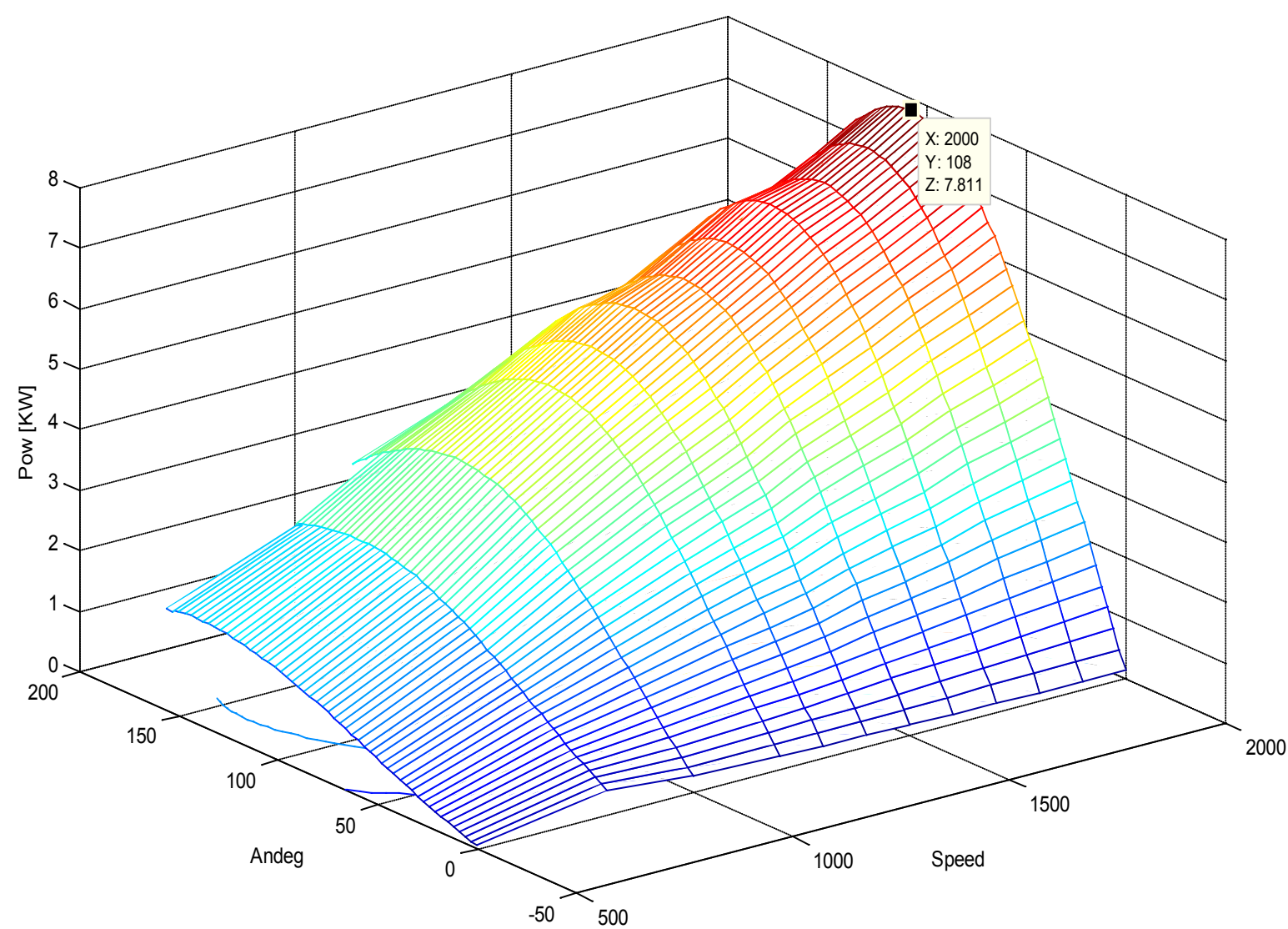

Figure 12. Comparative results of influence of the speed on the power

Fig. 12 depicts three-dimensional representation in terms of the power for our PMSG. The results show the power become higher as the rotational speed increase.

Fig. 13 shows simultaneously the effect of rotor speed on the power and the efficiency of PMSG, an increasing in rotor speed of the PMSG which is turned by the turbine causes an increasing in the power and the output at the same time.

\subsection{Rotor Length}

Fig. 14 illustrate simultaneously the power and the efficiency vs rotor length, the power increases almost linearly with the increasing of rotor length, but the efficiency increases nonlinearly with the increasing of the rotor length up to the value $60 \mathrm{~mm}$, because the active surface was increased, practically the efficiency is constant between $60 \mathrm{~mm}$ and $70 \mathrm{~mm}$, the efficiency decreases if the length of the rotor is increased because the rotor is longer than the stator, so more the losses additive.

\subsection{Infl uence of pole-Number on PMS G Char acteristics}

Cogging torque is due to the non-uniformity of the airgap reluctance due to slotting. It is independent of current excitation and proportional to the square of the flux-density[14], this is particularly important in wind generators since it raises the cut-in wind speed, thereby lowering the energy captured yield for a given installed capacity. Pulsating torques also produces noise and mechanical vibrations which accelerate the wear of the mach ine and its support structure[14].

The simulation results of cogging torque for six PMSG structures; when one varies only the number of poles by the FEA are shown in figure 15 , one can see clearly that the number of poles influence directly the cogging torque in pulsations and magnitudes.

The following figure show the effect of the number of stator slots on cogging torque, according to our results one can say that the increase in number of stator slots gives an increase in amplitude of cogging torque, but does not change its frequency as we can equally be observed.

Fig. 17 shows the efficiency as a function of electrical degree and the number of poles, no variation of curvatures is remarked, but a variation in amplitude is found, or the efficiency increases by $76.9 \%$ to $86 \%$ for the increase in number of poles from 2 to 10 respectively.

On the other hand the efficiency decreases if the number of poles increases; the efficiency reached the value $84.8 \%$ if the number of poles is 14 .

The variation power of PMSG as a function of number of poles and mechanical angle is showed in figure 18, it is noticed that the wave form is similar, but one sees a power peak of 7KW if our PMSG designed by 8 number of poles. 


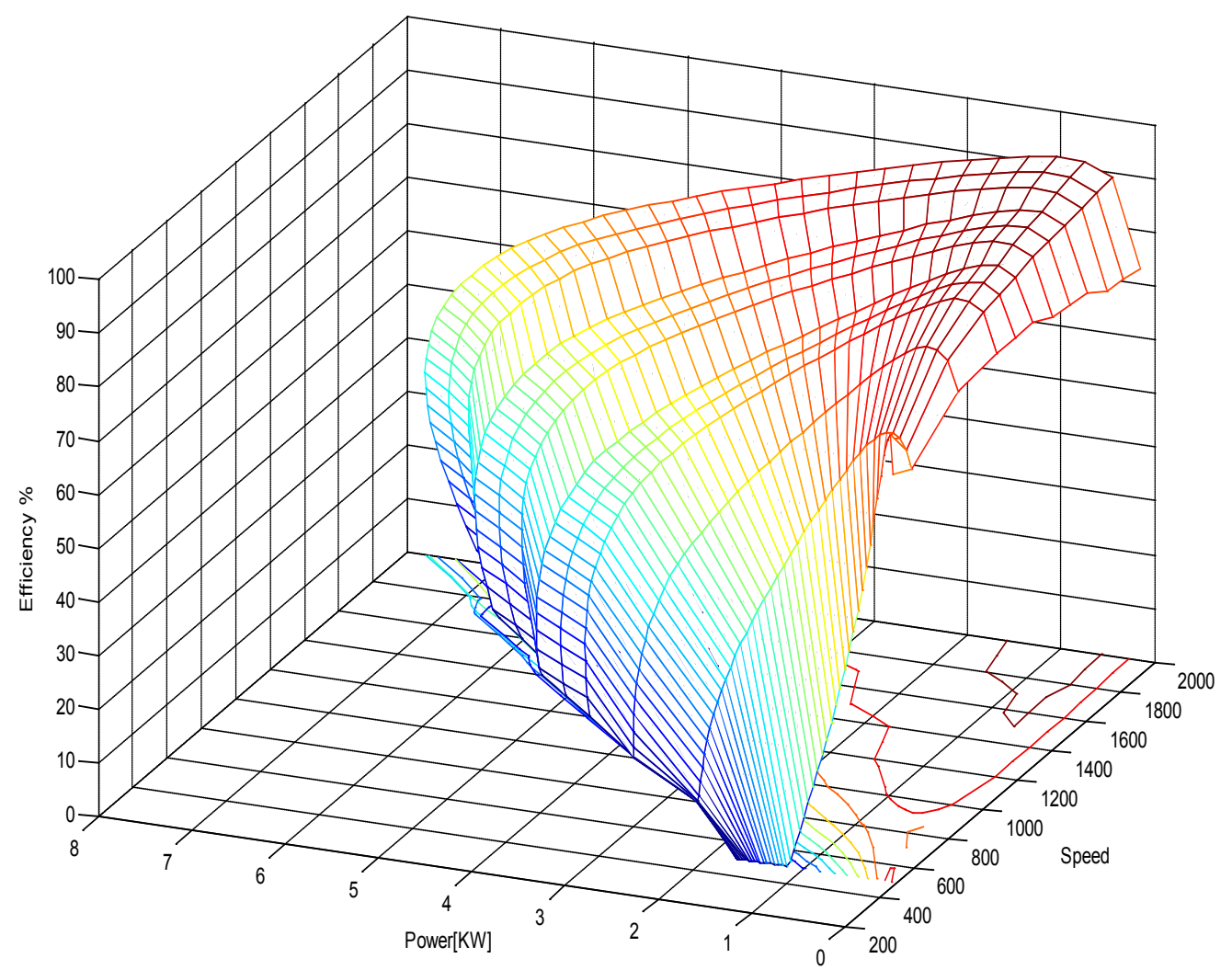

Figure 13. Comparison results of the speed effect on efficiency and power

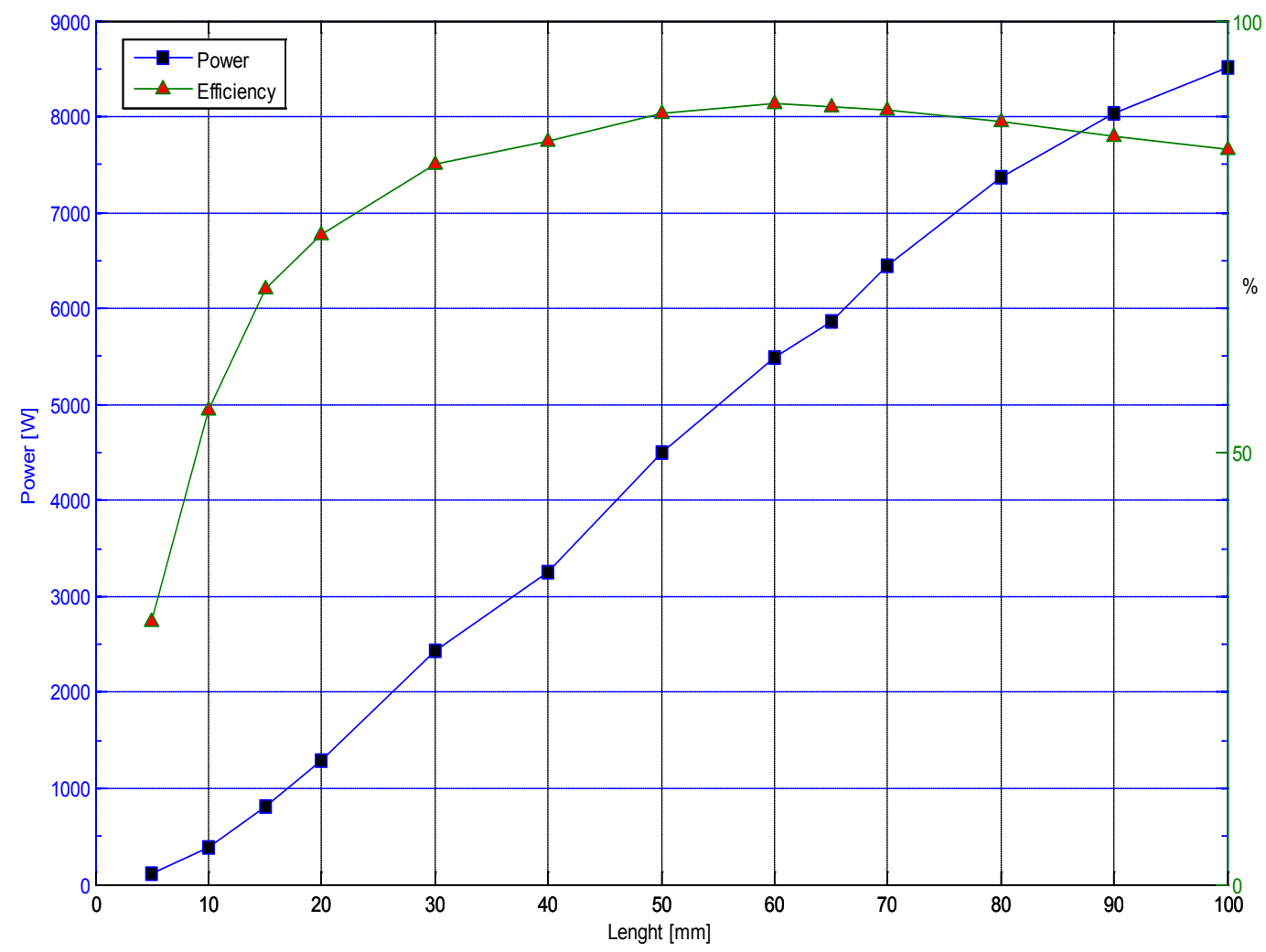

Figure 14. Power and efficiency vs rotor length 


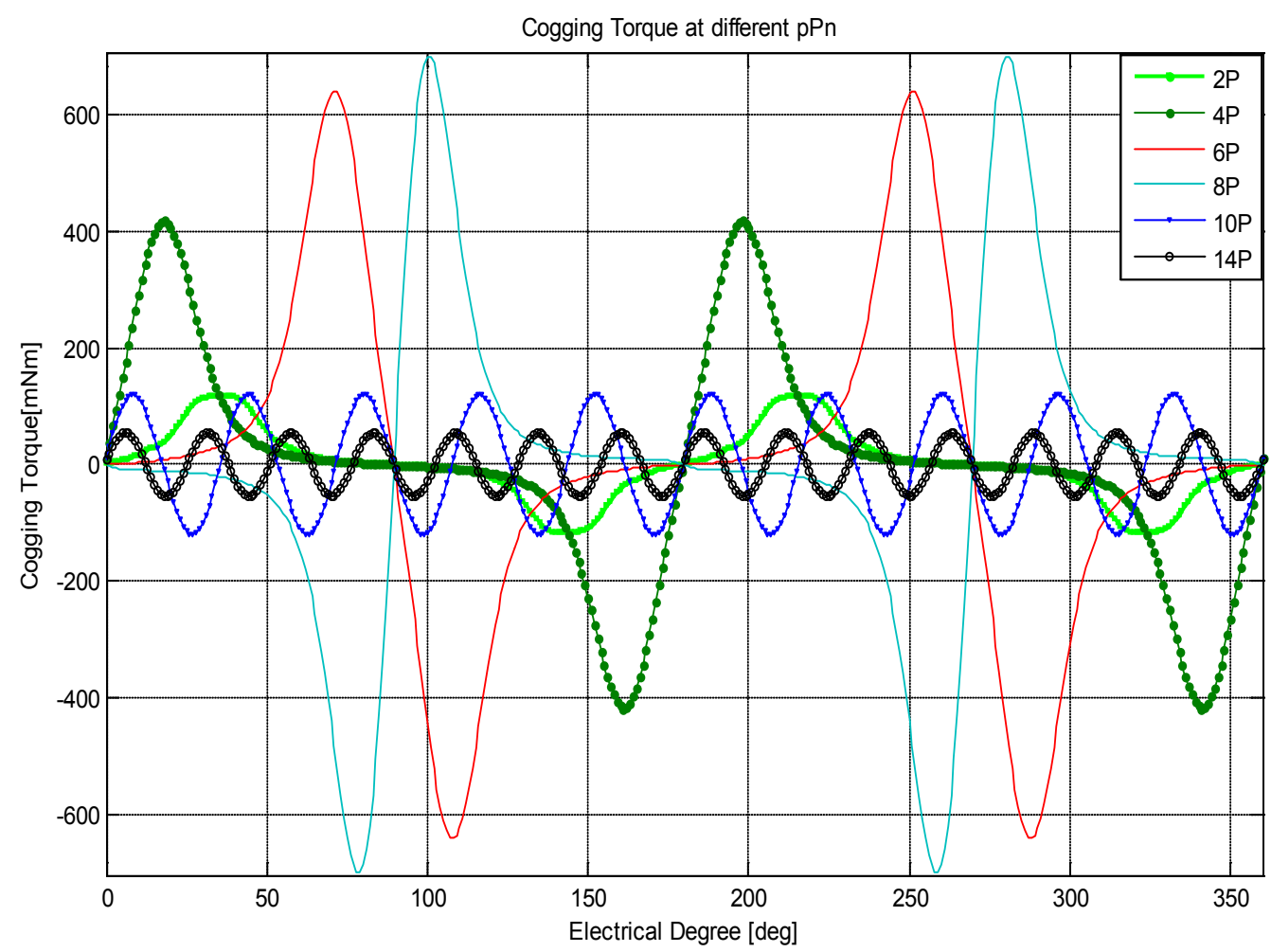

Figure 15. Influence of number of poles on cogging torque

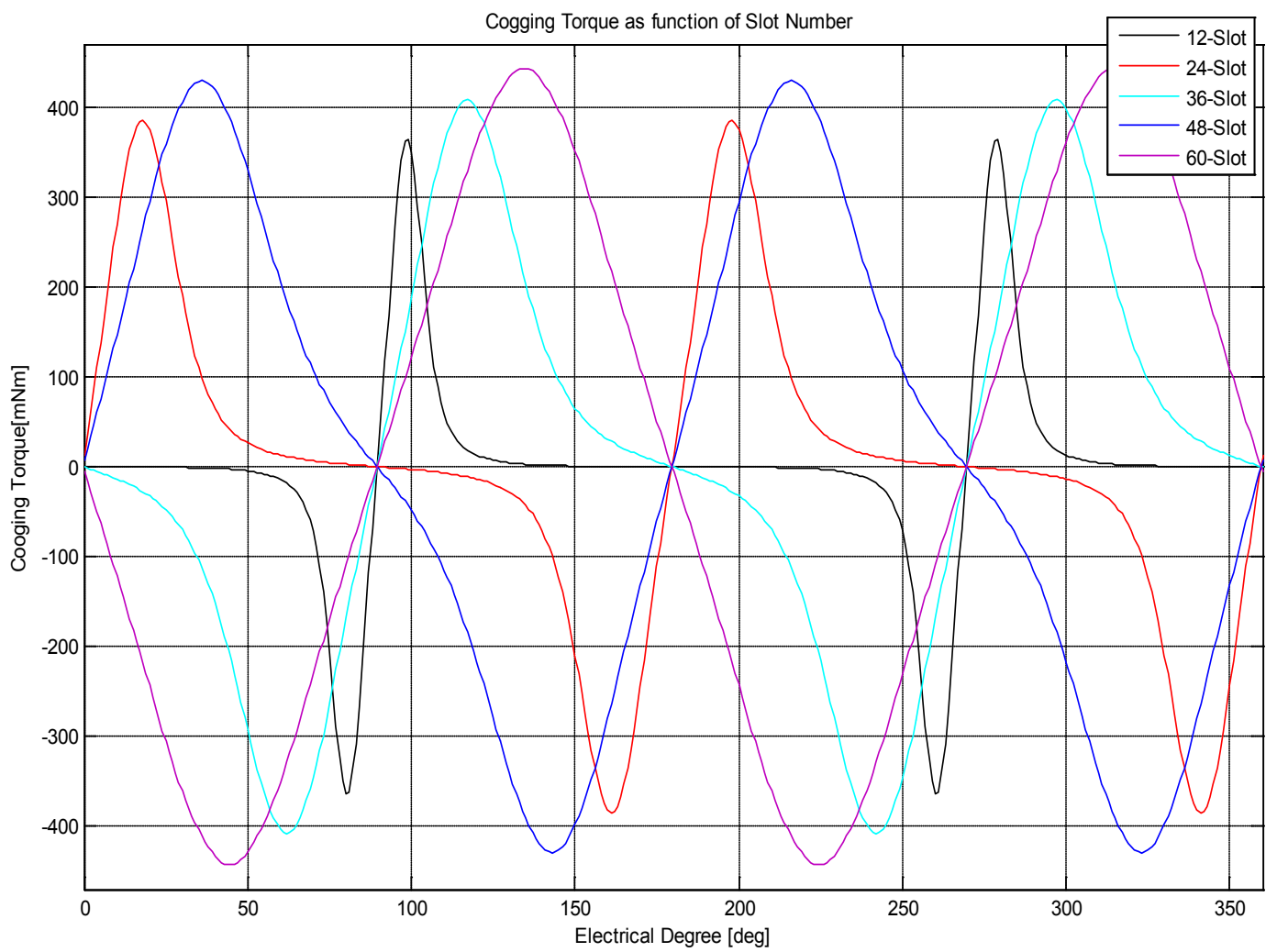

Figure 16. Influence of number of stat or slots on cogging torque 


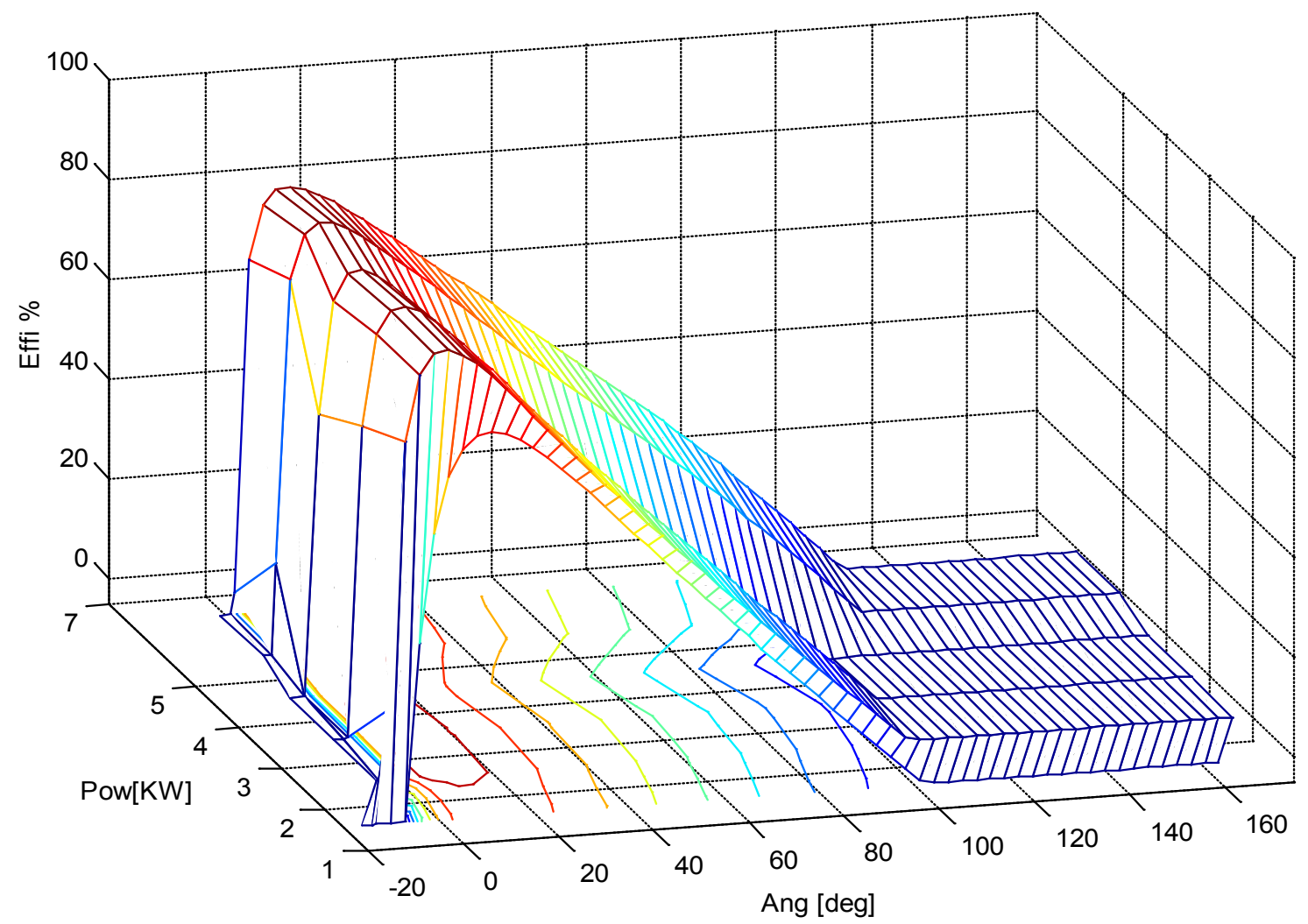

Figure 17. A comparative curve of PMSG efficiency's as a function of number of stat or pair poles and rot or electrical degree

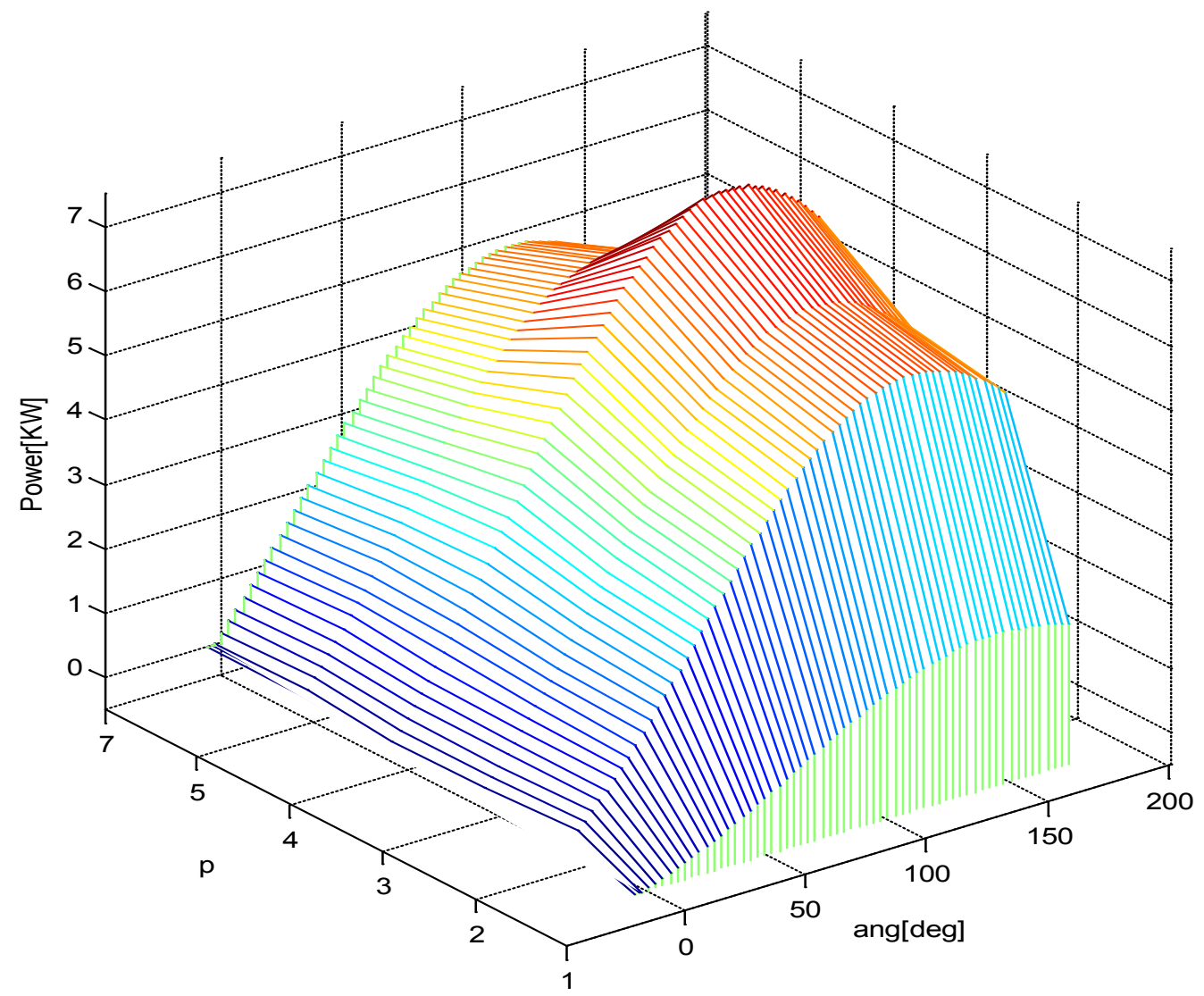

Figure 18. A comparative curve of PMSG power's as a function of number of stat or pair poles and rotor electrical degree 


\section{Conclusions}

Numerical analysis of magnetic field, e.g. FEA, can take into account the detailed structure and dimensions of the machine and the nonlinearity of the ferromagnetic materials, and hence can accurately compute the machine parameters and performances.

The type of PM used in the design of PMSG masters the majority of performances; it was found that among the PMs used the best performance is given by NDFE. It was found that the rotor speed influences proportionally on the power and the efficiency. The efficiency and power increase with the increasing of rotor length, but the efficiency decreases with the increasing of the rotor length, if it is bigger than the stator length, therefore its optimal value is $65 \mathrm{~mm}$.

According to showed results, the magnitude of the PMSG's cogging torque is affected by number of poles and number of stator slots, but the frequency of the PMSG's cogging torque is affected only by the number of stator slots, the optimal value of the number of poles and number of stator slots which guaranteed simultaneously these performances is 4 and 24 respectively.

FEM has proved to be a competent and valuable tool to study and design of PMSGs used in small wind power generation systems. The analys is results help to improve the generator design aspects.

\section{REFERENCES}

[1] A. Olimpo, J. Nick, E. Janaka, C. Phill and H Mike,Wind Energy Generation Modelling and Control, John Wiley \& Sons, Ltd 2009.

[2] I. Woofenden, wind power for dummies, Wiley Publishing, 2009.

[3] A. Petersson, Analysis, Modeling and Control of Doubly-Fed Induction Generators for Wind Turbines, $\mathrm{PhD}$ thesis, Chalmers university of technology, GÖteborg, Sweden 2005.
[4] M. O. L. Hansen, Aerodynamics of Wind Turbines, Second edition published by Earthscan in the UK and USA in 2008

[5] H. Li1, Z. Chen, H. Polinder, research report on models for numerical evaluation of variable speed different wind generator systems, Integrating and strengthening the European Research Area, 2002-2006.

[6] Z. Fang, Permanent magnet machine topologies for wind power generation, University of Sheffield, 2010.

[7] İ. Tarımer, C. Ocak, Performance Comparison of Internal and External Rotor Structured Wind Generators Mounted From Same Permanent Magnets on Same Geometry, Electronics And Electrical Engineering, Sins 1392 - 12152009.

[8] H. Li, Z. Chen, Overview of different wind generator sy stems and their comparisons, Renewable Power Generation, IET 2007.

[9] A. Parviainen, Design of axial-flux permanent-magnet low-speed machines and performance comparison between radial-flux and axial-flux machines, Lappeenrannan teknillinen yliopisto, Lapp eenranta University of Technology, 2005 .

[10] M. Haavisto, H. Kankaapaa, and M. Paju, Estimation of Time-Dependent Polarization Losses in Sintered Nd-Fe-B Permanent, IEEE transactions on Magnetics, vol. 47, no. 1, January 2011.

[11] Z. guo, L. chang, FEM Study on Permanent Magnet Synchronous Generators for Small Wind Turbines, IEEE 2005.

[12] H. Mellah, K.E Hemsas, Dynamic design and simulation analysis of permanent magnet motor in different scenario of fed alimentation, conference international on automatique and mécatronique novembre 22 -23, 2011, usto, Oran, Algeria, 2011.

[13] Help of Ansoft Maxwell V12®, Ansoft Corporation 2010.

[14] J. G. Wanjiku, H. Jagau, M. A. Khan, and P. S. Barendse, Minimization of Cogging Torque in a Small Axial-Flux PMSG with a Parallel-teeth Stator, IEEE 2011. 